\title{
Preparation of gelatin beads treated with glucose and glycerol
}

\author{
Débora Vieira Way', Márcio Nele² and José Carlos Pinto ${ }^{1 *}$ \\ 'Programa de Engenharia Química, Instituto Alberto Luiz Coimbra de Pós-graduação e Pesquisa em \\ Engenharia - COPPE, Universidade Federal do Rio de Janeiro - UFRJ, Rio de Janeiro, RJ, Brasil \\ ${ }^{2}$ Departamento de Engenharia Química, Escola de Química - EQ, Universidade Federal do \\ Rio de Janeiro - UFRJ, Rio de Janeiro, RJ, Brasil \\ *pinto@peq.coppe.ufrj.br
}

\begin{abstract}
Gelatin is employed in pharmaceutical applications because of its biodegradability, biocompatibility and low toxicity. However, it may be necessary to promote gelatin crosslinking in order to develop drug release systems and extend release times. SEC analyses are used here for the first time to monitor the evolution of molar mass distributions of gelatins during treatment with glycerol and glucose in dispersed media. Unambiguous experimental evidence of gelatin crosslinking in presence of sugars and glycerol has yet to be presented. SEC results indicate that average molar masses decrease during gelatin treatment, while FT-IR analyses indicate that gelatins are subject to structural modifications during processing, which can explain the decrease of gelatin solubility after treatment. The results presented here indicate the importance of using SEC techniques to monitor gelatin crosslinking, as they seemingly contradict previously published results that make use of indirect measures for this purpose.
\end{abstract}

Keywords: crosslinking, gelatin, size exclusion chromatography, SEC, molar mass distribution.

\section{Introduction}

Gelatin is a generic name used to describe proteins produced from the chemical hydrolysis of collagen ${ }^{[1,2]}$. The fabrication procedure, usually known as "conditioning process", can exert pronounced influence on the final properties of the obtained protein (or gelatin). Collagen can be hydrolyzed through alkali-conditioning or acid-conditioning, leading to type A (acid) or type B (basic) gelatins, presenting distinct isoelectric points ${ }^{[1-3]}$. The collagen structure comprises three alpha chains, which are coiled into a left-handed helix, originating the well-known triple-helix structure. When it is subjected to the conditioning process, the triple-helix is partially broken to form gelatin ${ }^{[1,4]}$. Gelatin is an inexpensive, biodegradable, biocompatible and non-toxic protein. Because of this, its use as an encapsulating material has been extensively studied in pharmaceutical applications ${ }^{[1]}$.

Drug encapsulation can offer various practical benefits for pharmaceutical applications, including masking of bad taste and odor of drugs, protection against photobleaching and oxidation, and development of controlled and/or targeted release of encapsulated bioactive molecules ${ }^{[5,6]}$. When hydrophilic polymers such as gelatin are used for drug encapsulation, it can be useful to crosslink the polymer chains in order to promote the decrease of the polymer solubility in body fluids and extend the release time of the drug ${ }^{[7]}$. (Although the term crosslinking can be used to describe different physico-chemical phenomena, in the present manuscript the term crosslinking is used to describe the formation of covalent chemical bonds among gelatin macromolecules with the mediation of smaller molecules, called crosslinking agents.) However, gelatin coating has also been proposed as an alternative to gelatin crosslinking ${ }^{[8]}$. Some of the most cited gelatin crosslinking agents are glutaraldehyde ${ }^{[9-11]}$, formaldehyde ${ }^{[1,12,13]}$, glyoxal ${ }^{[13,14]}$ and 1-ethyl-3-(3-dimethylaminopropyl) carbodiimide hydrochloride (EDC) ${ }^{[15,16]}$. Nevertheless, all the previously cited compounds are toxic and therefore should be avoided when pharmaceutical applications are pursued.

In order to replace the reported toxic compounds for natural non-toxic gelatin crosslinking agents, some authors reported the use of genipin ${ }^{[17]}$, dialdehyde $\operatorname{starch}^{[18]}$ and polyphenol ${ }^{[17,19]}$, for example. Many studies have also proposed the use of native and/or oxidized sugars, including dextran ${ }^{[20-22]}$, fructose $\mathrm{e}^{[23]}$ and glucose $\mathrm{e}^{[2,23]}$. In all the selected studies concerning the use of sugars, the crosslinking reaction time was usually small and in the range from 5 to 10 minutes ${ }^{[20-23]}$. Authors that report gelatin crosslinking usually do so by presenting indirect analytical data as drug release reduction ${ }^{[9,22]}$ or as consumption of free amino groups ${ }^{[10,12,16]}$ or also by presenting information of decrease in gelatin solubility ${ }^{[14,21,23]}$. These results do not undoubtedly prove the crosslinking reaction occurrence as the effects observed could also be caused by other side reactions. Nevertheless, some authors presented evidences of viscosity increase ${ }^{[13,20]}$ or FT-IR (Fourier transform infrared spectroscopy) analyse ${ }^{[10,11]}$ that could actually prove that reactions had happened in the reacting medium. However, despite the results reported in these studies, unambiguous experimental evidence of gelatin microparticle crosslinking 
in presence of sugars (and glycerol) has never been presented, as formation of solid particles can be due to physico-chemical effects other than crosslinking, such as modification of chain composition and configuration.

Based on the previous discussion, in the present paper SEC (Size Exclusion Chromatography) analyses were used for the first time to monitor the evolution of molar mass distributions of gelatins, when these materials were treated with glycerol and glucose. Particularly, one must observe that molecular weight distributions can be very sensitive to occurrence of crosslinking reactions, as formation of a single average covalent bond between the existing macromolecules can cause the doubling of the average molecular weights. Additionally, even when crosslinking takes place at high levels and leads to formation of insoluble material, the molecular weight distributions of the soluble fractions are expected to change considerably. For this reason, SEC analyses were performed to evaluate the importance of crosslinking reactions during thermal treatment of gelatin with glucose and glycerol.

\section{Materials and Methods}

\subsection{Materials}

Pigskin gelatin (240-270 Bloom), PhEur gelatin, Sorbitan monooleate $\left(\mathrm{SPAN}^{\circledR} 80\right)$ and D-(+)-Glucose ACS reagent were purchased from Sigma-Aldrich (Rio de Janeiro, Brazil) as pharmaceutical grades. Glycerol, acetone and sodium dodecyl sulfate (SDS) were obtained from VETEC (Rio de Janeiro, Brazil) with minimum purity of $99.5 \%$. Sunflower oil was purchased from Liza (Rio de Janeiro, Brazil) as a nutritional grade. Doxycycline hyclate (99\%) was purchased from Pharma Nostra (Goiás, Brazil). All reagents were used without further purification.

\subsection{Reactions}

Initially, glucose or glycerol was dissolved in $30 \mathrm{~g}$ of distilled water at $60^{\circ} \mathrm{C}$ in a glass flask. Then, $3 \mathrm{~g}$ of gelatin were added into the flask and the mixture was kept under continuous magnetic stirring at $60^{\circ} \mathrm{C}$ until solubilization of the protein and obtainment of a clear transparent solution. The solution was then poured into a previously prepared mixture containing $120 \mathrm{~g}$ of sunflower oil and $6 \mathrm{~g}$ of SPAN ${ }^{\circledR} 80$, kept at the desired reaction temperature $\left(50^{\circ} \mathrm{C}\right.$ or $\left.60^{\circ} \mathrm{C}\right)$, in order to avoid particle coalescence and allow for preparation of regular droplets of gelatin solution, as stabilized by SPAN ${ }^{\circledR}$. The resulting reaction mixture was kept under vigorous magnetic stirring at 50 or $60^{\circ} \mathrm{C}$ for $30 \mathrm{~min}$ and $2 \mathrm{~mL}$ aliquots were withdrawn at regular intervals of 5 minutes for further analyses. Operation conditions were selected in accordance with previously published references ${ }^{[23-25]}$. After the reaction step, the reaction medium was cooled down to $10{ }^{\circ} \mathrm{C}$ and then $30 \mathrm{ml}$ of acetone were added into the reaction flask in order to promote the dehydration of the gelatin droplets and obtain gelatin particles. The product was then filtrated, washed with abundant amounts of acetone (for removal of residual oil and water) and kept in desiccators at room temperature to prevent absorption of water.

When doxycycline was used in the reactions, $1.5 \mathrm{~g}$ was solubilized in water and heated to $60^{\circ}$ before adding the gelatin. The rest of the procedure was reproduced exactly as described above, but the reaction was conducted for only 20 minutes.

\subsection{SEC analyses}

The chromatographic system comprised three OH-PAK SB-806 (Shodex, Japan) columns connected in series, a Phenomenex TS-430 separation module (Phenomenex, United States) and a Viscotek VE358 refractive index detector (Viscotek, United Kingdom). The running conditions and sample preparation procedures were defined in accordance with previously published material ${ }^{[26]}$. The mobile phase (18 g/L of SDS in Milli-Q water) was filtrated through $0.45 \mu \mathrm{m}$ filters prior to use. Sample preparation consisted in dissolving $1 \mathrm{mg}$ of samples of the produced gelatin particles in $1 \mathrm{~mL}$ of the SDS solution at room temperature. Before injection, all samples were filtrated through $0.22 \mu \mathrm{m}$ syringe filters. It is important to emphasize that clear and transparent solutions were obtained in all cases. Samples of $200 \mu \mathrm{L}$ were then injected into the SEC device and run for $80 \mathrm{~min}$ at flow rates of $0.5 \mathrm{~mL} / \mathrm{min}$ at $40{ }^{\circ} \mathrm{C}$. The equipment was calibrated with poly(styrene sulfonate) standards (American Polymer Standards Corporation, United States) ranging from 3420 to $2350000 \mathrm{Da}$.

\section{4 FT-IR analyses}

FT-IR analyses were performed in a Thermo Nicolet 6700 FT-IR spectrometer (Nicolet, United States) equipped with a diamond Smart Orbit accessory for direct analyses of solid samples. The Smart Orbit accessory is shown in Figure 1. Infrared analyses were performed in the mid-infrared region in total reflection mode with resolution of $4 \mathrm{~cm}^{-1}$ at room temperature. Spectral data were reported as averages of 128 scans.

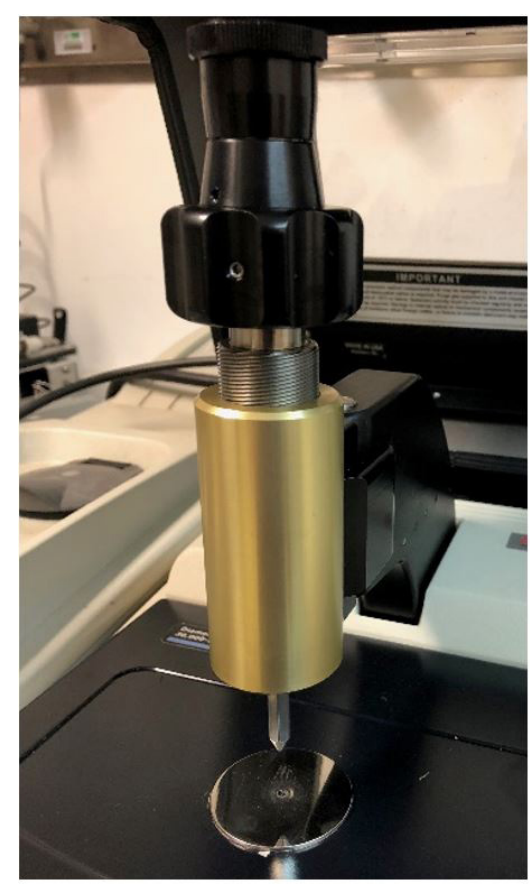

Figure 1. Smart orbit accessory. 


\section{Results and Discussions}

As gelatins may have distinct characteristics, it is important to characterize these materials before use because small differences between them may cause different behaviors during the reactions. Table 1 shows the detailed amino acid composition of the analyzed gelatins, as provided by Biosynthesis (Texas, United States). As one can see in Table 1, the analyzed gelatins were not very different in terms of amino acid compositions, although small composition changes can affect significantly the concentration of a particular functional group. Gelatins were also characterized by size exclusion chromatography (SEC), as shown in Figure 2, and by optical microscopy, as shown in Figure 3. Results indicate that the molar mass distributions of both gelatins were very similar, but that $\mathrm{PhEur}$ gelatin has smaller particle size distribution when compared to Pigskin gelatin. According to Dupont ${ }^{[26]}$, gelatins can undergo hydrolysis upon aging, leading to increase of gelatin fractions of low molar mass, especially around 14,000 Da. However, as one can see in Figure 3, the original raw materials presented high average molar masses and small fractions of low molar masses, indicating that gelatins had not been subject to significant aging.

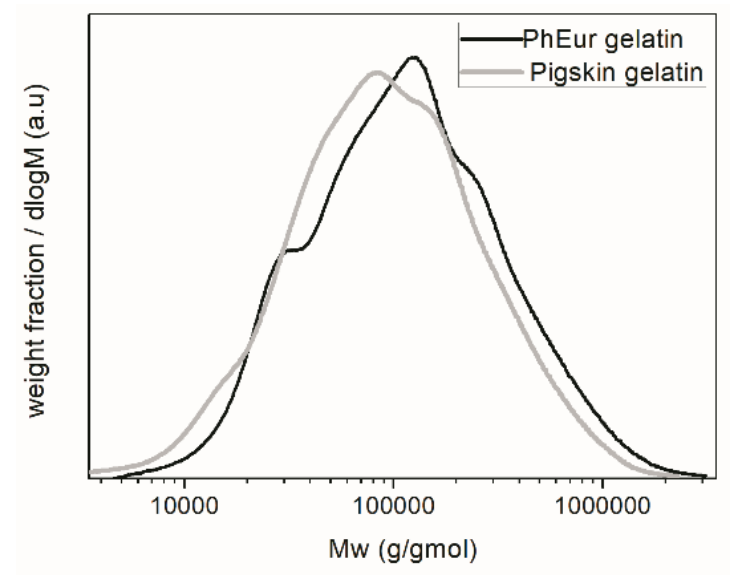

Figure 2. Weight average molar mass distributions of the original gelatins before treatment.

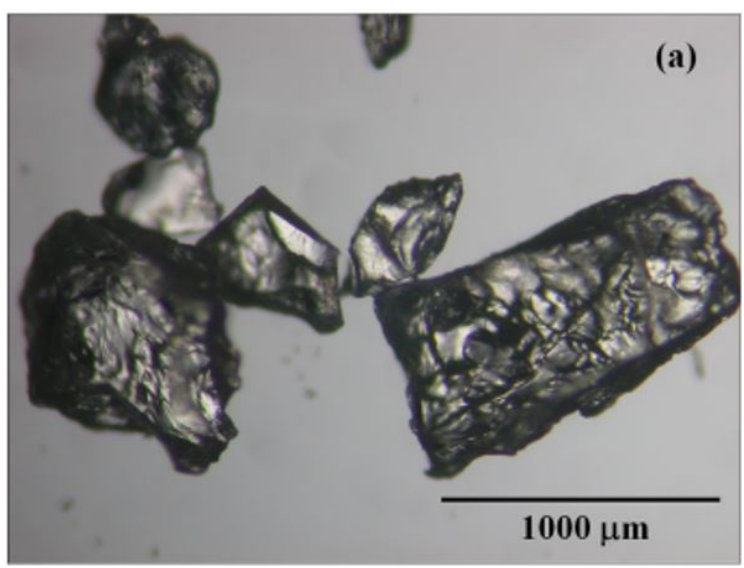

The $\mathrm{pHs}$ of aqueous solutions of $\mathrm{PhEur}$ and pigskin gelatin $(0.1 \mathrm{~g} / \mathrm{mL})$ were measured in order to avoid reaction processing in the vicinities of the isoelectric points (IP). This precaution is necessary to allow for complete solubilization of gelatin in the aqueous phase. The results are shown in Table 2 and confirm that the analyzed gelatins belong to group A (acid gelatins) and are expected to dissolve in acidic media.

Table 3 presents the full set of gelatin treatment runs analyzed in the present manuscript. Runs were performed

Table 1. Amino acid composition of the analyzed gelatins.

\begin{tabular}{|c|c|c|}
\hline Aminoacid & $\begin{array}{c}\text { PhEur Gelatin } \\
\text { Composition } \\
(\mathrm{mol} \%)\end{array}$ & $\begin{array}{c}\text { Pigskin Gelatin } \\
\text { Composition } \\
(\mathrm{mol} \%)\end{array}$ \\
\hline Hydroxyproline & 13.47 & 12.84 \\
\hline $\begin{array}{l}\text { Aspartic acid and } \\
\text { asparagine }\end{array}$ & 5.51 & 5.25 \\
\hline Serine & 2.82 & 2.78 \\
\hline $\begin{array}{l}\text { Glutamic acid and } \\
\text { glutamine }\end{array}$ & 10.11 & 9.72 \\
\hline Glycine & 21.18 & 21.51 \\
\hline Histidine & 1.32 & 1.33 \\
\hline Arginine & 8.67 & 8.84 \\
\hline Threonine & 1.86 & 1.85 \\
\hline Alanine & 8.60 & 8.54 \\
\hline Proline & 13.14 & 13.96 \\
\hline Cysteine & 0.00 & 0.00 \\
\hline Tyrosine & 0.65 & 0.86 \\
\hline Valine & 2.09 & 1.68 \\
\hline Methionine & 0.71 & 0.91 \\
\hline Lysine & 3.93 & 3.97 \\
\hline Isoleucine & 1.23 & 1.13 \\
\hline Leucine & 2.82 & 2.75 \\
\hline Phenylalanine & 1.99 & 2.08 \\
\hline Tryptophan & 0.00 & 0.00 \\
\hline
\end{tabular}

Table 2. $\mathrm{pH}$ of aqueous gelatin solutions $(0.1 \mathrm{~g} / \mathrm{mL})$.

\begin{tabular}{cccc}
\hline Gelatin & $\mathbf{p H}$ & Classification & IP range* $^{*}$ \\
\hline PhEur & 5.76 & Type A & 7 to 9 \\
Pigskin & 5.51 & & \\
\hline *According to Gelatin Manufacturers Institute of America GMIA
\end{tabular}

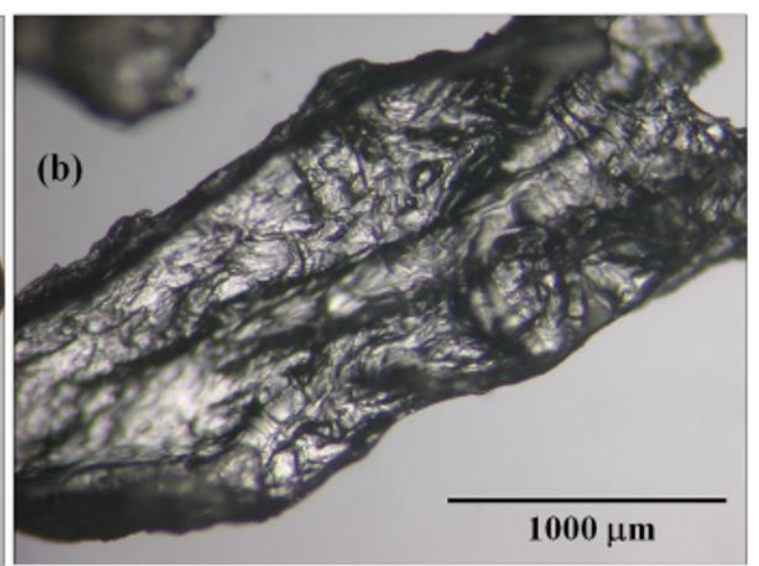

Figure 3. Optical micrographs of samples of the original PhEur (a) and Pigskin (b) gelatins. 
with distinct concentrations of crosslinking agents, distinct gelatins and at different reaction temperatures. Also, one reaction was performed with doxycycline (DOX), used as a model drug, to simulate a real condition in which a drug is encapsulated to observe the reaction behavior. The $\mathrm{pHs}$ of the prepared aqueous solutions were measured to ensure that $\mathrm{pH}$ values were significantly below the isoelectric points of the gelatins, as already discussed.

Figure 4 shows the evolution of the average molar masses of the analyzed samples in Run\#1 to Run\#7 and compares them to PhEur gelatin average molar mass before any kind of treatment. One can observe that for Run\#1 the average molar masses decreased from $197000 \mathrm{~g} / \mathrm{mol}$ to $153000 \mathrm{~g} / \mathrm{mol}$ (approximately 22\%) in the very beginning of the expected crosslinking process when compared to PhEur gelatin before the reaction, remaining essentially constant after 5 minutes of treatment. At this point, one must observe that the reaction time was assumed to start after preparation of the inverse suspension, so that it did not include the time required for preparation of the initial aqueous solution of gelatin, which took approximately 10 minutes. This explains the sudden decrease of the average molecular weights of treated gelatins when the reaction time was equal to zero, reflecting the fast modification of the gelatin properties during the preparation of the initial aqueous gelatin solution.

Based on Figure 4, it is possible to infer that glucose was not acting as a crosslinking agent at the analyzed conditions. More interestingly yet, similar trends were observed when additional amounts of glucose were used, as shown in Figure 4, although the average molar mass decrease reached $37 \%, 35 \%$ and $28 \%$ in Run\#2, Run\#3 and Run\#4, respectively. More specifically, the average molar masses decreased from $197000 \mathrm{~g} / \mathrm{mol}$ in PhEur gelatin to $123000 \mathrm{~g} / \mathrm{mol}$ in Run\#2, to $129000 \mathrm{~g} / \mathrm{mol}$ in Run\#3 and to $142000 \mathrm{~g} / \mathrm{mol}$ in Run\#4. Therefore, it seems plausible to admit that glucose was not acting as a crosslinking agent during gelatin treatment at the analyzed conditions, despite the previously reported data. This highlights the importance of using techniques that can actually prove the crosslinking occurrence other than indirect analytical methods, that can lead to misleading conclusions.

Similar results were obtained at different treatment temperatures and when glycerol was used as the crosslinking agent, as also illustrated in Figure 4. Moreover, the observed results were essentially the same when different molar mass averages were used to observe the evolution of the molecular weights, due to the very similar molecular weight distributions of the analyzed samples. Particularly, published material reports the possible occurrence of spontaneous gelatin crosslinking after exposure to higher temperatures ${ }^{[27]}$, which could not be confirmed in the temperature range of $50-60{ }^{\circ} \mathrm{C}$ at the analyzed conditions, as shown in Figure 4 for treatment temperature of $60^{\circ} \mathrm{C}$. Finally, Figure 4 shows that the weight average molar masses of the final products were very similar in all cases, indicating that the addition of glucose and glycerol to the reaction medium exerted little effect on the evolution of molar masses in the analyzed experiments.

Figure 5 exemplifies the molecular weight distribution of the produced gelatins and Figure 6 shows that it was possible to produce gelatin microparticles. Figure 6 also shows that the particles produced tend to form small aggregates that are probably formed after the drying procedure.

Despite the results presented in Figure 4, one point must be emphasized. The operation pressure of the SEC equipment increased steadily with the reaction time, indicating some sort of consistent structural change of the gelatin structure or formation of nanogel that could not be removed through filtration in all runs. This can be regarded as an indirect evidence of slight increase of molecular weights (that could not be detected through the SEC calibration curve) or of decrease of gelatin solubility due to modification of the macromolecular conformation and stereo configuration. One must observe that gelatin is known to be a thixotropic

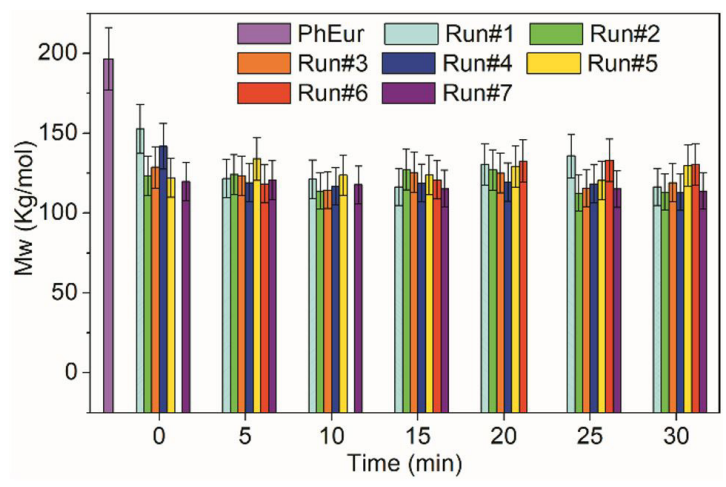

Figure 4. Evolution of weight average molar mass from Run\#1 to Run\#7.

Table 3. Operation conditions used in gelatin treatment experiments.

\begin{tabular}{|c|c|c|c|c|c|c|}
\hline Run & Gelatin & Glycerol (\%) & Glucose (\%) & Doxycycline (g) & $\begin{array}{c}\text { Temperature } \\
\left({ }^{\circ} \mathrm{C}\right)\end{array}$ & $\mathrm{pH}^{* *}$ \\
\hline 1 & PhEur & - & 1 & - & 50 & 5.4 \\
\hline 2 & PhEur & - & 2 & - & 50 & 4.4 \\
\hline 3 & PhEur & - & 3 & - & 50 & 4.0 \\
\hline 4 & PhEur & - & 4 & - & 50 & 4.0 \\
\hline 5 & PhEur & 10 & - & & 50 & 5.3 \\
\hline 6 & PhEur & - & - & - & 50 & 5.8 \\
\hline 7 & PhEur & - & - & - & 60 & 5.8 \\
\hline 8 & Pigskin & - & 4 & - & 50 & 5.5 \\
\hline 9 & PhEur & - & - & 0.75 & 60 & 1.4 \\
\hline
\end{tabular}

**pH was measured immediately after the complete solubilization of gelatin and before dispersion in sunflower oil. 

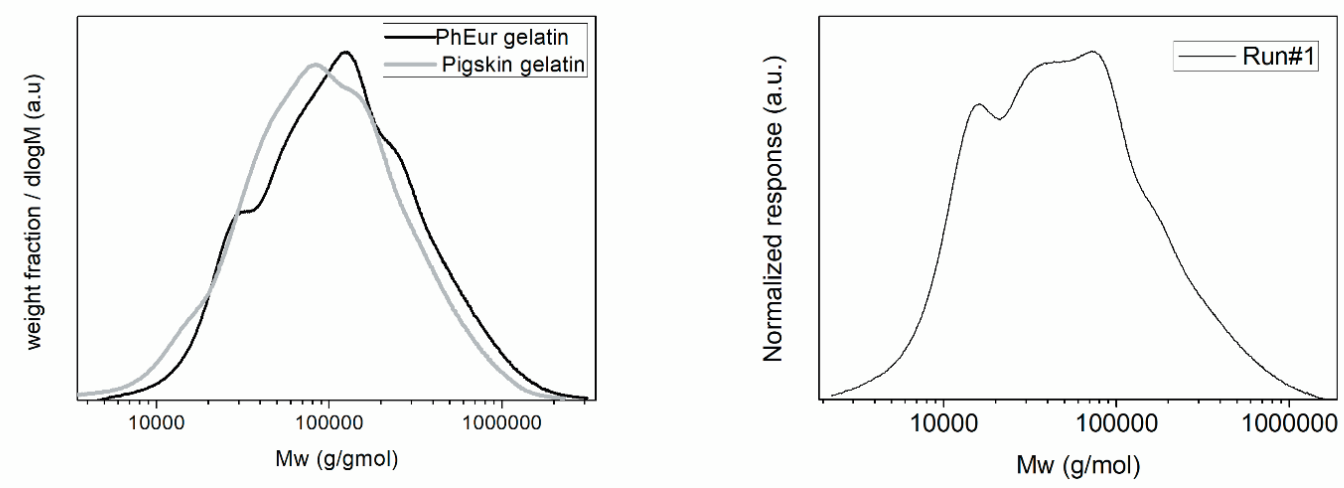

Figure 5. Molecular weight distributions of gelatin samples of the original material and of the final product of Run\#1.

material ${ }^{[28]}$, so that the viscosity of a gelatin solution is expected to change under stress, which can magnify pressure fluctuations of the SEC equipment associated with the modification of the gelatin structure.

Figure 7 shows FT-IR spectra of gelatin samples treated in absence of crosslinking agents. It can be noticed that the intensity of the band positioned at $3274 \mathrm{~cm}^{-1}$ increased considerably (in relation to the main peaks located at 3420 and $1700 \mathrm{~cm}^{-1}$ ) for the PhEur gelatin when glucose or glycerol were not used. This region is usually assigned for existence of amide A and amide B bonds, which are characteristic of peptide chains, as also reported in Table 4. In order to observe more clearly the existence of bands related to amides I, II and III bonds, Figure 7 was enlarged, as shown in Figure 8, that also shows the relative increase of the bands that characterize the amides I, II and III bonds. Hence, as chemical compounds were not added to the reaction medium in order to promote the formation of $\mathrm{C}=\mathrm{O}$ or NH functional groups, it seems plausible to assume that structural modification of the gelatin occurs spontaneously during the thermal treatment at the analyzed conditions.

Susy and Byler ${ }^{[29]}$ studied the IR deconvolution of amide I bands and related the observed changes to modifications of protein secondary structures. Based on these previous observations, the shape and position of the amide I band obtained in the present study probably corresponds to the $\alpha$-helix conformation. Assuming that this is correct, as the intensity of the amide I band increases during the reaction treatment, it seems plausible to assume that the characteristic triple helix structure of collagen (which is partially destroyed when gelatin is produced) is still being affected by the thermal treatment process during the analyzed experiments. This conjecture can also be supported by the available SEC analyses, as the decrease of average molar masses can possibly be related to the residual degradation of the triple helix structure and formation of the $\alpha$-helix structure, as degradation of the triple helix structure would necessarily lead to the relative increase of the lower molecular weight fractions of analyzed samples.

Similar results could be obtained when glycerol and glucose were added to the reaction medium, as shown in Figures 9 and 10, reinforcing the assumption that these chemicals do not act as crosslinking agents during the gelatin treatment in the analyzed conditions. Particularly,

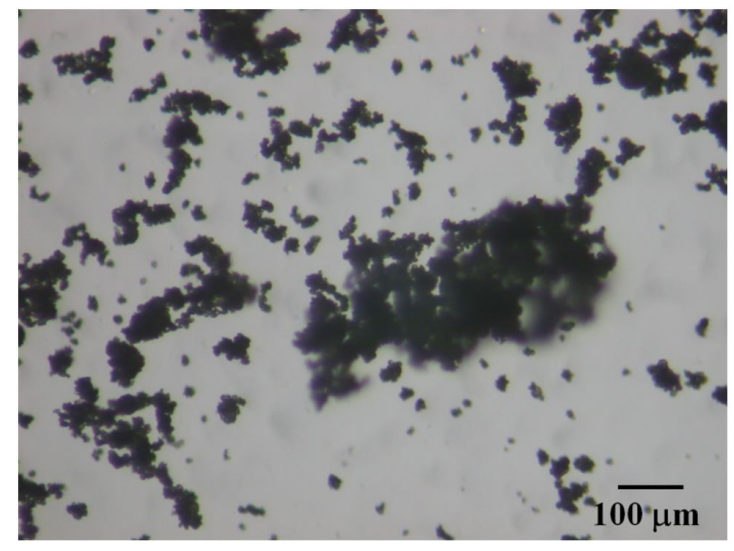

Figure 6. Optical micrograph of gelatin particles produced in Run\#1.

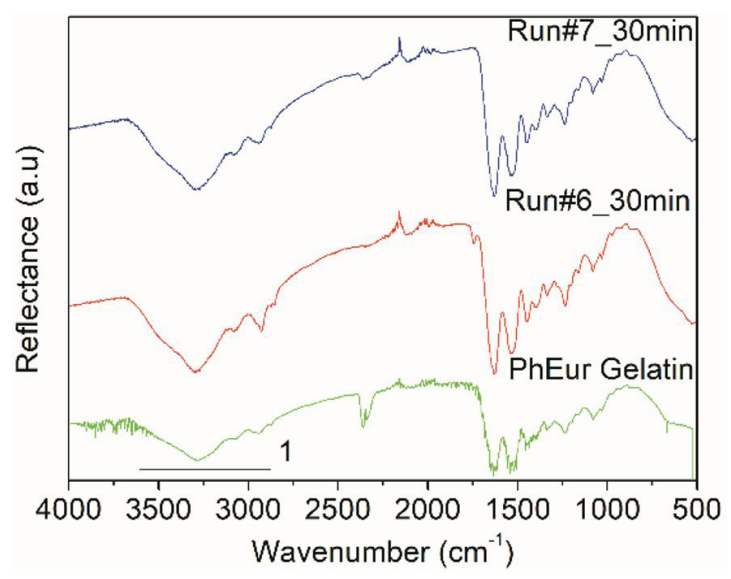

Figure 7. FT-MIR spectra of gelatin samples treated in absence of crosslinking agents.

Figure 10 compares FT-IR results obtained after thermal treatment in presence of glucose with samples prepared through mixing of all reagents, as described in the previous section, but not submitted to thermal treatment. It can be noticed that mixing is not sufficient to promote the FT-IR changes described previously, indicating once more that the 
Table 4. Characteristic infrared bands of gelatins ${ }^{[30]}$.

\begin{tabular}{cccc}
\hline Identification & Frequencies & Designation & Vibrational mode \\
\hline 1 & $3300 \mathrm{~cm}^{-1}$ & Amide A & NH stretching \\
& $3100 \mathrm{~cm}^{-1}$ & Amide B & NH stretching \\
2 & $1700-1600 \mathrm{~cm}^{-1}$ & Amide I & Approximately $80 \%$ of the peptidic linkages C=O stretching \\
3 & $1480-1575 \mathrm{~cm}^{-1}$ & Amide II & $\mathrm{CN}$ stretching, NH bending \\
4 & $1229-1301 \mathrm{~cm}^{-1}$ & Amide III & $\mathrm{CN}$ stretching, NH bending \\
\hline
\end{tabular}

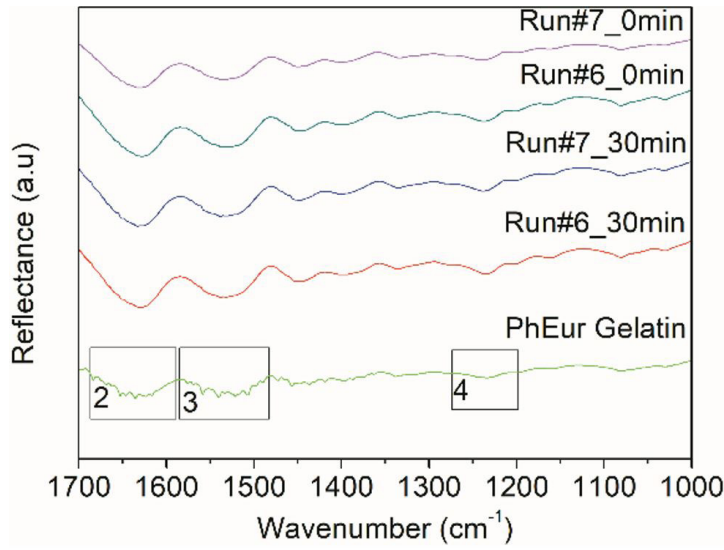

Figure 8. Partial FT-MIR spectrum (1700 to $1000 \mathrm{~cm}^{-1}$ ).

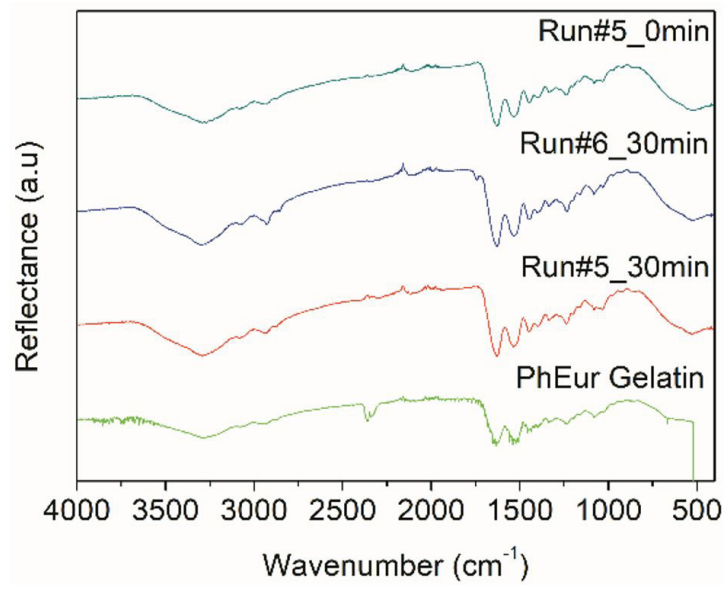

Figure 9. FT-MIR spectra of gelatin samples treated with glycerol (Run\#5).

thermal treatment leads to spontaneous modifications of the gelatin structure. Figure 11 shows that the observed FT-IR changes were similar for both analyzed gelatins, indicating that the observed FT-IR modifications did not depend on the particularly analyzed gelatin structure.

Based on the obtained results, it seems reasonable to assume that glucose and glycerol do not act as gelatin crosslinking agents at the analyzed conditions and that the modification of gelatin properties observed after thermal treatment is related mostly to the residual modification of the characteristic triple helix structure of collagen. It must be observed that modification of the gelatin structure is

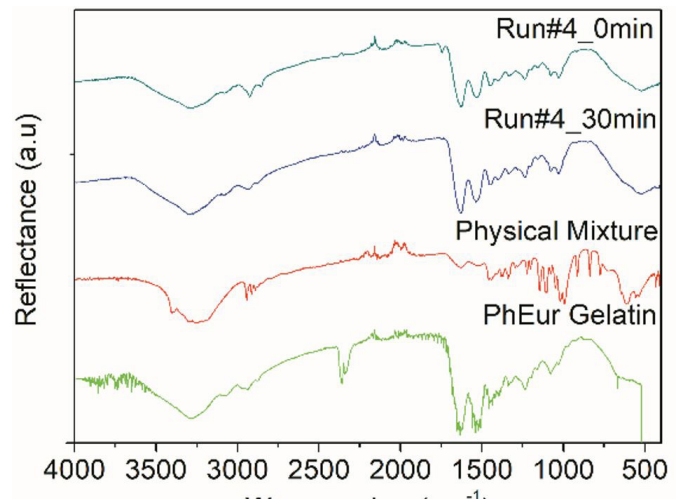

Figure 10. FT-MIR spectra of gelatin samples treated with glucose (Run\#4).

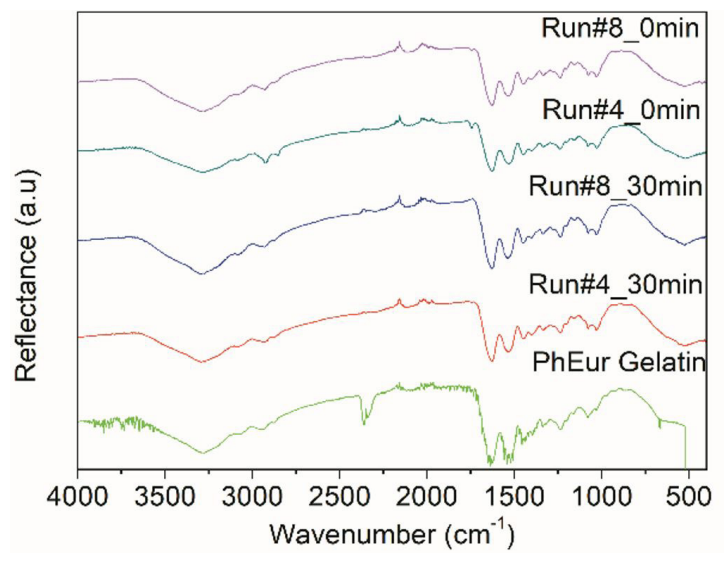

Figure 11. FT-MIR spectra of gelatin samples treated with glucose (Run\#4 and Run\#8).

fast at the analyzed conditions, as the most significant modifications of the weight average molar masses take place in less than 10 minutes at the analyzed treatment conditions. As a consequence, addition of glycerol and glucose to the reaction medium at the analyzed conditions do not improve significantly the properties of gelatin particles produced in oil suspensions.

Doxycycline (DOX) is a broad sprectrum antibiotic used both in human and animal treatment and, therefore, a drug of great interest for the Pharmaceutical industry ${ }^{[31,32]}$. As can be noted in Figure 12, that shows the chemical structure of doxycycline, it presents multiple acid and amine groups that 
could possibly crosslink gelatin. Therefore, one more test was conducted using DOX to observe if it could engage in crosslinking reactions.

As shown in Figure 13, the decrease in the weight average molar mass in Run\#9 right in the beginning of the reaction is less than 3\% when compared to PhEur gelatin before any kind of treatment. Comparing this result to the previously reported reactions, in which the decreases in the average molar masses were in order of $30 \%$, it seems plausible to admit that doxycycline may be interacting with gelatin.

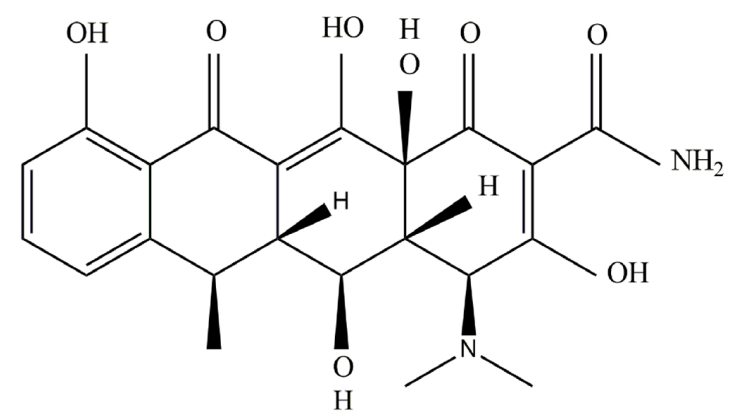

Figure 12. Chemical structure of doxycycline.

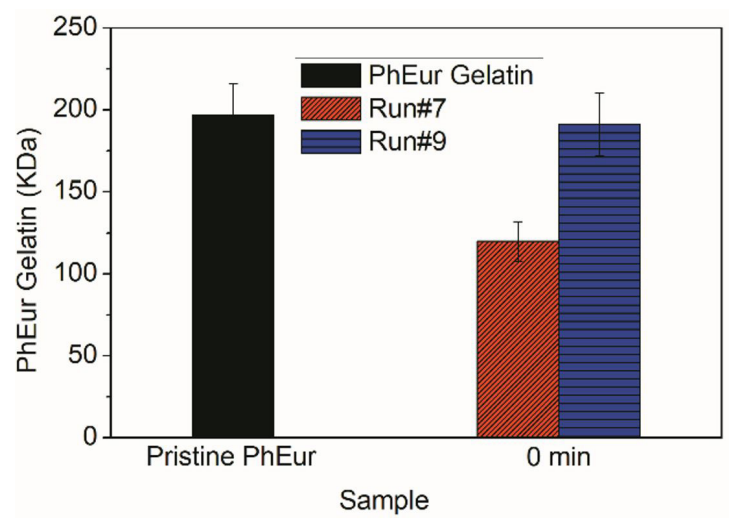

Figure 13. Weigh average molar mass of pristine PhEur gelatin and weigh average molar masses of Runs \#7 and \#9 in the beginning of the reaction.

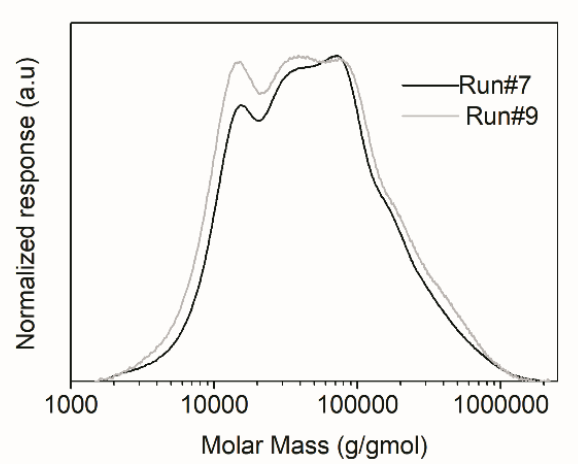

Figure 14. SEC analysis of the final product of Run\#7 and \#9.
Besides, in Run\#9 after 20 min of reaction, the decrease reached only $23 \%$ and as can be seen in Figure 14, the molar mass is broader than in Run\#7 and slightly dislocated to higher molar masses. As the only difference between Run\#7 and Run\#9 is the use of doxycycline and the decrease observed in Run\#7 was $\sim 39 \%$, two simultaneous fenomena may be occurring. The first one is observed by the decrease in molar mass and is associated to the structural modifications of gelatin already discussed. Besides, as doxycycline molar mass is only $545 \mathrm{~g} / \mathrm{mol}$, it seems likely to assume that the very discrete $3 \%$ decrease in the molar mass can not be associated to a simple interaction between gelatin and doxycycline. Therefore, the second fenomena observed is the increase in gelatin molar mass, that is probably caused by the crosslinking of gelatin by doxycycline.

Based on the obtained results, it can be concluded that the proposed SEC technique seems appropriate to monitor the evolution of molar mass distributions of gelatins. Obtained SEC results indicated that the average molar masses decreased during the gelatin treatment and FT-IR (Fourier Transform Infrared Spectroscopy) analyses indicated that gelatins were subject to structural modifications during processing, which can eventually explain the decrease of gelatin solubility in water after treatment observed by other groups. Particularly, based on the obtained results it could be concluded that glucose and glycerol did not act as gelatin crosslinking agents at the analyzed conditions (temperatures ranging from $50{ }^{\circ} \mathrm{C}$ to $60{ }^{\circ} \mathrm{C}$, maximum reaction times of $30 \mathrm{~min}$, gelatin concentration of $10 \mathrm{wt} \%$, crosslinking agent concentration below $10 \mathrm{wt} \%$ and $\mathrm{pH}$ values below 5.8), despite previous dats reported in the literature. Moreover, the modification of gelatin properties observed after thermal treatment was related mostly to the residual modification of the characteristic triple helix structure of collagen. As a consequence, addition of glycerol and glucose to the reaction medium at the analyzed conditions did not improve significantly the properties of gelatin particles produced in oil suspensions. Therefore, the results presented in this paper emphasize the importance of using unambiguous experimental techniques to investigate gelatin crosslinking.

\section{Conclusions}

A size exclusion chromatograph (SEC) procedure was proposed and successfully used to monitor the evolution of molar mass distributions of gelatins in aqueous solutions. As observed at different conditions (temperatures ranging from $50{ }^{\circ} \mathrm{C}$ to $60^{\circ} \mathrm{C}$, maximum reaction times of $30 \mathrm{~min}$, gelatin concentration of $10 \mathrm{wt} \%$, crosslinking agent concentration below $10 \mathrm{wt} \%$ and $\mathrm{pH}$ values below 5.8), the use of glycerol and glucose did not allow for effective crosslinking of gelatin samples treated in inverse suspensions, as evaluated through SEC and despite previous reports based on indirect crosslinking characterization. Finally, doxycycline was shown to act as a crosslinking agent for gelatin.

\section{Acknowledgements}

The authors thank CNPq (Conselho Nacional de Desenvolvimento Científico e Tecnológico, Brazil) and FAPERJ (Fundação Carlos Chagas Filho de Amparo à 
Pesquisa do Estado do Rio de Janeiro, Brazil) for supporting this research and providing scholarships.

\section{References}

1. Schrieber, R., \& Gareis, H. (2007). Gelatin handbook. Germany: Wiley VCH. http://dx.doi.org/10.1002/9783527610969.

2. Digenis, A., Gold, T., \& Shah, V. (1994). Cross-linking of gelatin capsules and its relevance to their in vitro-in vivo performance. Journal of Pharmaceutical Sciences, 83(7), 915-921. http:// dx.doi.org/10.1002/jps.2600830702. PMid:7965669.

3. Gelatin Manufacturers Institute of America - GMIA. (2012). Gelatin handbook. Retrieved from http://www.gelatin-gmia. com/images/GMIA_Gelatin_Manual_2012.pdf

4. Yannas, I. (1972). Collagen and gelatin in the solid state. Journal of Macromolecular Science, 7(1), 49-106. http://dx.doi. org/10.1080/15321797208068160.

5. Desai, M. P., Labhasetwar, V., Amidon, G. L., \& Levy, R. J. (1996). Gastrointestinal uptake of biodegradable microparticles: effect of particle size. Pharmaceutical Research, 13(12), 1838-1845. http://dx.doi.org/10.1023/A:1016085108889. PMid:8987081.

6. Esposito, E., Cortesi, R., \& Nastruzzi, C. (1996). Gelatin microspheres: influence of preparation parameters and thermal treatment on chemico-physical and biopharmaceutical properties. Biomaterials, 17(20), 2009-2020. http://dx.doi. org/10.1016/0142-9612(95)00325-8. PMid:8894096.

7. Vandelli, M., Romagnoli, M., Monti, A., Gozzi, M., Guerra, P., Rivasi, F., \& Forni, F. (2004). Microwave-treated gelatin microspheres as drug delivery system. Journal of Controlled Release, 96(1), 67-84. http://dx.doi.org/10.1016/j. jconrel.2004.01.009. PMid:15063030.

8. Khan, S., \& Schneider, M. (2014). Stabilization of gelatin nanoparticles without crosslinking. Macromolecular Bioscience, 14(11), 1627-1638. http://dx.doi.org/10.1002/mabi.201400214. PMid:25154300.

9. Fan, H., \& Dash, A. (2001). Effect of cross-linking on the in vitro release kinetics of doxorubicin from gelatin implants. International Journal of Pharmaceutics, 213(1-2), 103-116. http:// dx.doi.org/10.1016/S0378-5173(00)00651-7. PMid:11165098.

10. Farris, S., Song, J., \& Huang, Q. (2010). Alternative reaction mechanism for the cross-linking of gelatin with glutaraldehyde. Journal of Agricultural and Food Chemistry, 58(2), 998-1003. http://dx.doi.org/10.1021/jf9031603. PMid:20043635.

11. Ulubayram, K., Eroglu, I., \& Hasirci, N. (2010). Gelatin microspheres and sponges for delivery of macromolecules. Journal of Biomaterials Applications, 16(3), 227-241. http:// dx.doi.org/10.1177/0885328202016003178. PMid:11939457.

12. Zampieri, A., Lima, E., \& Diniz, D. (2005). Estudo da ligação cruzada induzida pelo formaldeído em cápsulas de gelatina dura. Revista Eletrônica de Farmácia, 2(2), 73-79.

13. Davis, P., \& Tabor, B. (1963). Kinetic study of the crosslinking of gelatin by formaldehyde and glyoxal. Journal of Polymer Science Part A, 1(2), 799-815. http://dx.doi.org/10.1002/ pol.1963.100010217.

14. Carvalho, R., \& Grosso, C. (2005). properties of chemically modified gelatin films. Brazilian Journal of Chemical Engineering, 23(1), 45-53. http://dx.doi.org/10.1590/S010466322006000100006.

15. Lai, J. (2010). Biocompatibility of chemically cross-linked gelatin hydrogels for ophthalmic use. Journal of Materials Science. Materials in Medicine, 21(6), 1899-1911. http:// dx.doi.org/10.1007/s10856-010-4035-3. PMid:20238149.

16. Lai, J. (2011). Evaluation of cross-linking time for porous gelatin hydrogels on cell sheet delivery performance. Journal of Mechanics in Medicine and Biology, 11(5), 967-981. http:// dx.doi.org/10.1142/S0219519411004873.

17. Zhao, Y., \& Sun, Z. (2017). Effects of gelatin-polyphenol and gelatin-genipin cross-linking on the structure of gelatin hydrogels. International Journal of Food Properties, 20(3S), 2822-2832. http://dx.doi.org/10.1080/10942912.2017.13811 11.

18. Kaczmarek, B., Sionkowska, A., Monteiro, F. J., Carvalho, A., Łukowicz, K., \& Osyczka, A. M. (2018). Characterization of gelatin and chitosan scaffolds cross-linked by addition of dialdehyde starch. Biomedical Materials (Bristol, England), 13(1), 015016. http://dx.doi.org/10.1088/1748-605X/aa8910. PMid:29244656.

19. Madhan, B., Subramanian, V., Rao, J. R., Nair, B. U., \& Ramasami, T. (2005). Stabilization of collagen using plant polyphenol: Role of catechin. International Journal of Biological Macromolecules, 37(1-2), 47-53. http://dx.doi.org/10.1016/j. ijbiomac.2005.08.005. PMid:16183110.

20. Schacht, E., Bogdanov, E., Bulcke, B., \& De Rooze, A. (1997). Hydrogels prepared by crosslinking of gelatin with dextran dialdehyde. Reactive \& Functional Polymers, 33(2-3), 109116. http://dx.doi.org/10.1016/S1381-5148(97)00047-3.

21. Cortesi, R., Esposito, E., Osti, M., Menegatti, E., Squarzoni, G., Spencer Davis, S., \& Nastruzzi, C. (1999). Dextran crosslinked gelatin microspheres as a drug delivery system. European Journal of Pharmaceutics and Biopharmaceutics, 47(2), 153-160. http://dx.doi.org/10.1016/S0939-6411(98)00076-9. PMid:10234540.

22. Wu, H., Zhang, Z., Wu, D., Zhao, H., Yu, K., \& Hou, Z. (2006) Preparation and drug release characteristics of pingyangmycinloaded dextran cross-linked gelatin microspheres for embolization therapy. Journal of Biomedical Materials Research. Part B, Applied Biomaterials, 78(1), 56-62. http://dx.doi.org/10.1002/ jbm.b.30458. PMid:16333847.

23. Cortesi, R., Nastruzzi, C., \& Davis, S. (1998). Sugar crosslinked gelatin for controlled release: microspheres and disks. Biomaterials, 19(18), 1641-1649. http://dx.doi.org/10.1016/ S0142-9612(98)00034-9. PMid:9839999.

24. Ulubayram, K., Eroglu, I., \& Hasirci, N. (2002). Gelatin microspheres and sponges for delivery of Macromolecules. Journal of Biomaterials Applications, 16(3), 227-241. http:// dx.doi.org/10.1177/0885328202016003178. PMid:11939457.

25. Wang, C., Ai, D., Chen, C., Lin, H., Li, J., Shen, H., Yi, W., Qi, Y., Wu, H., \& Cao, J. (2009). Preparation and evaluation of danofloxacin mesylate microspheres and its pharmacokinetics in pigs. Veterinary Research Communications, 33(8), 1013-1022. http://dx.doi.org/10.1007/s11259-009-9320-6. PMid:19774478.

26. Dupont, A. (2002). Study of the degradation of gelatin in paper upon aging using aqueous size-exclusion chromatography. Journal of Chromatography. A, 950(1-2), 113-124. http:// dx.doi.org/10.1016/S0021-9673(02)00010-9. PMid:11990984.

27. Yannas, I., \& Tobolsky, A. (1967). Cross-linking of gelatine by dehydration. Nature, 215(5100), 509-510. http://dx.doi. org/10.1038/215509b0. PMid:6057911.

28. Djakovic, L., Sovilj, V., Milosevic, S., \& Sad, N. (2010). Rheological behaviour of thixotropic starch and gelatin gels. Starch, 42(10), 380-385. http://dx.doi.org/10.1002/ star. 19900421004.

29. Kong, J., \& Yu, S. (2007). Fourier transform infrared spectroscopic analysis of protein secondary structures. Acta Biochimica et Biophysica Sinica, 39(8), 549-559. http://dx.doi. org/10.1111/j.1745-7270.2007.00320.x. PMid:17687489.

30. Susi, H., \& Byler, D. (1986). Resolution-enhanced Fourier transform infrared spectroscopy of enzymes. Methods in Enzymology, 130, 290-311. http://dx.doi.org/10.1016/00766879(86)30015-6. PMid:3773736. 
31. Hanemaaijer, R., Visser, H., Koolwijk, P., Sorsa, T., Salo, T., Golub, L. M., \& van Hinsbergh, V. W. (1998). Inhibition of MMP Synthesis by Doxycycline and Chemically Modified Tetracyclines (CMTs) in Human Endothelial Cells. Advances in Dental Research, 12(2), 114-118. http://dx.doi.org/10.1177 /08959374980120010301. PMid:9972133.
32. Joshi, N., \& Miller, D. (1997). Doxycycline revisited. Archives of Internal Medicine, 157(13), 1421-1428. http://dx.doi. org/10.1001/archinte.1997.00440340035003. PMid:9224219.

Received: Apr. 28, 2017 Revised: June 16, 2018 Accepted: July 04, 2018 